\title{
Serotonin Modulation of Sensory Inputs to the Lateral Amygdala: Dependency on Corticosterone
}

\author{
Grace E. Stutzmann, ${ }^{1}$ Bruce S. McEwen, ${ }^{2}$ and Joseph E. LeDoux ${ }^{1}$ \\ ${ }^{1}$ New York University, Center for Neural Science, New York, New York 10003, and ${ }^{2}$ Rockefeller University, Laboratory of \\ Neuroendocrinology, New York, New York 10021
}

\begin{abstract}
The lateral nucleus of the amygdala $(L A)$ receives excitatory (glutamatergic) inputs from thalamic and cortical sensory processing areas and is believed to be involved in evaluation of the affective significance of sensory events. We examined whether serotonin (5-HT) affects excitatory transmission in auditory afferents to the LA and, if so, whether this modulation of sensory transmission is regulated by the stress hormone corticosterone (CORT). Neuronal activity in the LA was elicited via iontophoretic ejection of L-glutamate or synaptically via electrical stimulation of auditory afferent pathways. In the intact rat, iontophoretically applied 5-HT inhibited both synaptically and glutamate-evoked action potentials in most neurons examined. However, after adrenalectomy (ADX), which eliminates endogenous CORT, 5-HT no longer inhibited evoked activity in the LA. High-CORT doses given to ADX animals reinstated the inhibi-
\end{abstract}

tion of excitatory transmission of 5-HT, whereas low-CORT doses had little effect. Immunocytochemical labeling of the glucocorticoid receptor in the intact rat demonstrated nuclear staining throughout several amygdala regions, including the LA. However, after ADX, no nuclear labeling was visible. With a high replacement dose of CORT (5 or $10 \mathrm{mg}$ ) after ADX, dense nuclear staining returned, but with a low replacement dose (1 $\mathrm{mg} / \mathrm{kg}$ ), there was only light nuclear staining. Thus, the ability of 5-HT to modulate glutamatergic activity in auditory pathways to the amygdala is dependent on the presence of CORT and possibly glucocorticoid activation. Via this mechanism, 5-HT modulates the processing of sensory information within the LA and thus may regulate amygdala-related functions.

Key words: amygdala; stress; corticosterone; serotonin; glutamate; rat
The amygdala has long been thought of as an interface between events in the environment and effector organs controlling behavioral, autonomic, and endocrine responses associated with emotional arousal and stress reactions (for review, see LeDoux, 1996). Fear-conditioning studies have been especially informative in elucidating how stimuli are processed by pathways that link sensory systems with the amygdala and thereby control emotional responses (Davis, 1992; LeDoux, 1994, 1996; Maren and Fanselow, 1996). Briefly, conditioned fear stimuli, such as a tone paired with foot shock, are transmitted to the lateral nucleus of the amygdala (LA) by monosynaptic glutamatergic afferents from the auditory thalamus and cortex (LeDoux et al., 1990; Farb et al., 1995; Li et al., 1995, 1996; Farb and LeDoux, 1997). Signals then reach the central amygdala (CE) (Pitkanen et al., 1997), which projects to several brain systems involved in autonomic and endocrine regulation, including the paraventricular nucleus of the hypothalamus (Kapp et al., 1992; Davis, 1994; LeDoux, 1996), which links the amygdala directly to the hypothalamic-pituitaryadrenal (HPA) axis (Gray, 1993). Via these pathways, the amygdala can transduce fear-conditioned stimuli or fearful events in the environment into a stress-activated response (McEwen and Sapolsky, 1995; LeDoux, 1996).

Activation of the HPA axis culminates in the release of the steroid hormone corticosterone (CORT), which then enters the

Received July 16, 1998; revised Aug. 20, 1998; accepted Aug. 28, 1998.

This work was supported by National Institute of Mental Health Grants RO1MH46516 and 1K02-MH00956 and the W. M. Keck Foundation. We thank Mian Hou and Claudia Farb for excellent technical assistance.

Correspondence should be addressed to Grace E. Stutzmann, New York University, Center for Neural Science, 4 Washington Place, Room 808, New York, NY 10003.

Copyright (ㄷ) 1998 Society for Neuroscience $\quad 0270-6474 / 98 / 189529-10 \$ 05.00 / 0$ brain and binds to receptors there. One class of CORT receptor is the low-affinity glucocorticoid receptor [(GR), type II], which is activated only during periods of elevated CORT. (McEwen et al., 1986; Herman et al., 1989; Sapolsky, 1996). The LA, basal (B), and $\mathrm{CE}$ nuclei of the amygdala contain a relatively high density of GR (Ahima and Harlen, 1991), suggesting that stress-induced release of CORT can activate GR and affect amygdala-related functions, such as emotional expression and neuroendocrine control. In addition, several studies have found that manipulation of GR in the amygdala affects other behavioral functions mediated by this region (Roozendaal et al., 1992; Roozendaal and McGaugh, 1997).

Dysfunctions of the HPA axis may be related to stress and affective disorders, and these are often alleviated by serotonergic compounds (Meltzer and Lowy, 1987). Consistent with this, the amygdala receives a dense 5-HT projection from the dorsal raphe nucleus, and activation of the dorsal raphe increases amygdala 5-HT levels and stimulates CORT release, demonstrating a potential means for direct serotonergic modulation of CORTinduced activity in the amygdala (Chaoloff, 1993; Kawahara et al., 1993). In turn, stress hormones stimulate serotonergic activity in the amygdala (Axelrod and Reisine, 1984; Boadle-Biber et al., 1993; Inoue et al., 1993; Laaris et al., 1995), suggesting that 5-HT-CORT interactions may be involved in amygdaladependent emotional and/or stress states.

Given the presence of 5-HT receptors in the amygdala (Radja et al., 1991), the known interactions between glucocorticoids and 5-HT (Popava and Lobacheva, 1982; Mendelson and McEwen, 1992; McKittrick and McEwen, 1996; Joels, 1997) and the role of serotonin in depression and anxiety (Curzon, 1988), it is important to explore how adrenal steroids interact with 5-HT and 


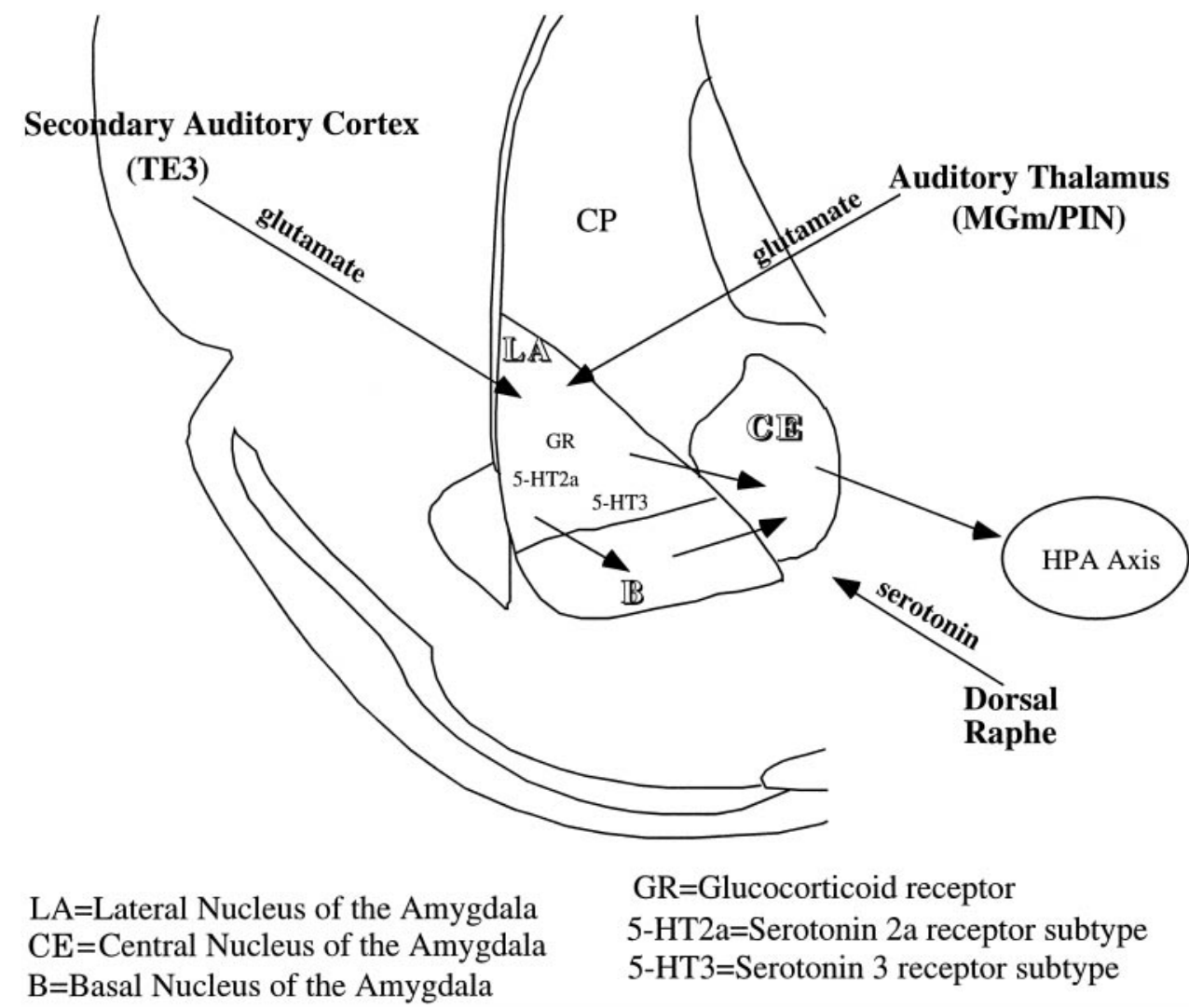

Figure 1. Schematic of the relevant pathways and receptors in the amygdala complex. The auditory thalamus (MGm/PIN) and cortex (TE3) send glutamatergic projections to the LA. The CE is the output nucleus of the amygdala and receives projections from both the LA and B and sends projections to paraventricular nucleus of the hypothalamus, connecting the amygdala complex to the HPA axis. The type II glucocorticoid receptor is found throughout the amygdala. The dorsal raphe sends a strong serotonergic projection to the amygdala complex with $5-\mathrm{HT}_{2 \mathrm{~A}}$ and $5-\mathrm{HT}_{3}$ receptors in the LA and $\mathrm{B}$ nuclei and $5-\mathrm{HT}_{1 \mathrm{~A}}$ receptors in the $\mathrm{CE}$ (data not shown).

\section{LA=Lateral Nucleus of the Amygdala $\mathrm{B}=$ Basal Nucleus of the Amygdala}

\section{$\mathrm{GR}=$ Glucocorticoid receptor \\ 5-HT2a=Serotonin 2a receptor subtype 5 -HT3=Serotonin 3 receptor subtype}

excitatory responses in the amygdala. In the present study, we therefore determined whether serotonin modulates sensory input processing in the amygdala, and if so, whether stress hormones, acting via the glucocorticoid receptor, can influence this processing. To accomplish this, we activated and recorded single units in the LA and measured the response to iontophoretically applied serotonin in the presence and absence of corticosterone.

\section{MATERIALS AND METHODS}

Experiments were conducted on male Sprague Dawley rats weighing 250-375 gm. All animals were housed on an alternating $12 \mathrm{hr}$ light/dark cycle (lights on 7:00 A.M., lights off at 7:00 P.M.). Procedures were performed in accordance with National Institutes of Health guidelines.

Adrenalectomy surgery. Rats (225-275 gm) were anesthetized with medetomidine $(0.5 \mathrm{mg} / \mathrm{kg}$, i.p.) and ketamine $(75 \mathrm{mg} / \mathrm{kg}$, i.p.). The region of the torso overlying the adrenal glands was shaved and wiped with a topical antiseptic. Longitudinal incisions were made over the adrenal glands and were gently retracted. Dissolvable sutures were used to rejoin the abdominal muscle wall, and the epidermis was closed with wound clips. The anesthetic reversing agent atipamezole $(0.5 \mathrm{mg} / \mathrm{kg}$, i.m.) and the analgesic butorphanol $(0.5 \mathrm{mg} / \mathrm{kg}$, i.m. $)$ were administered at the conclusion of the surgery. Saline $(0.9 \%)$ was provided to drink. At least $4 \mathrm{~d}$ were allowed for complete removal of endogenous CORT before any experimental procedures were implemented.

In vivo extracellular single unit recording with iontophoresis. The ability of 5-HT to modulate glutamate-evoked activity, as well as synaptic activity induced by stimulating afferents, was examined. Afferents stimulated included areas of the auditory thalamus [medial geniculate, medial nucleus/posterior intralaminar nucleus (MGm/PIN)] and auditory cortex (TE3) that project to the LA (LeDoux et al., 1990; Romanski and LeDoux, 1993). Previous studies have shown that stimulation of the MGm/PIN and TE3 regions and iontophoresis of glutamate will evoke measurable actions potentials in the LA (Li et al., 1995, 1996). Once parameters were determined for eliciting stable and consistent spikes (either by stimulation level or glutamate ejection current), 5-HT was concurrently iontophoresed. This was done in intact rats and in adrenalectomy (ADX) rats with and without CORT replacement. The ADX and
ADX plus CORT conditions were examined in the same animal. Briefly, the procedure was to record baseline activity and serotonergic modulation of excitatory transmission in the ADX animal, administer one of three doses of CORT ( $1 \mathrm{mg} / \mathrm{kg}, 5 \mathrm{mg}$, or $10 \mathrm{mg}$, s.c.), and repeat the stimulation-recording paradigm after $1 \mathrm{hr}$ to determine whether 5-HT changes in its modulation of synaptic and evoked activity. Figure 1 provides a schematic of the important pathways, receptors, and experimental setup.

Rats $(n=46)$ were anesthetized with urethane $(1.6 \mathrm{mg} / \mathrm{kg})$ and placed in a stereotaxic frame. Body temperature $\left(37^{\circ} \mathrm{C}\right)$ and depth of anesthesia were monitored throughout the experiment. The cranium above the LA, $\mathrm{MGm} / \mathrm{PIN}$, and TE3 regions were exposed, and the dura were retracted. Electrodes were then placed into the LA using a hydraulic microdrive, and bipolar stimulating electrodes were manually lowered into the $\mathrm{MGm} / \mathrm{PIN}$ region [inserted at a $10^{\circ}$ angle in the anteroposterior (AP) plane] and the TE3 region (inserted in a $20^{\circ}$ angle in the AP plane). The TE3 and MGm regions were stimulated with single pulses $(100-800 \mu \mathrm{A}$, $0.3 \mathrm{~Hz}, 300 \mu$ s duration) from a Grass 88 constant-current stimulator delivered through a bipolar stimulating electrode $(r=30-40 \mathrm{~K} \Omega)$. Electrode stereotaxic coordinates from the interaural line (in $\mathrm{mM}$ ) were as follows: recording electrode, AP 5.8-6.2; mediolateral (ML) 5.2; dorsoventral (DV) 6.0-7.0; MGm-stimulating electrode, AP 3.8; ML 3.0; DV 6.1; TE3-stimulating electrode, AP 4.0; ML 6.8; DV 3.3.

Single unit recordings were obtained from glass micropipettes $(1-3 \mu \mathrm{m}$ tip diameter, 10-20 M $\Omega$ impedance) filled with $2.5 \%$ Pontamine Sky Blue in $0.5 \mathrm{~m}$ sodium acetate. Single unit activity was amplified, filtered, and discriminated. Undiscriminated output was viewed on a Tektronix storage oscilloscope, and discriminated output was digitized for the construction of poststimulus histograms using a Cambridge Electronic Design 1401 computer interface (Science Park, Cambridge, UK).

Microiontophoresis was accomplished by gluing a five barrel micropipette (10-20 $\mu \mathrm{m}$ tip diameter) adjacent to the single barrel micropipette with a light curing dental fixative (Silux; 3M, St. Paul, MN). The tip of the recording pipette extended $15-35 \mu \mathrm{m}$ beyond the tip of the iontophoretic pipette. The center barrel was filled with $0.9 \%$ saline for automatic current balancing. The remaining barrels were filled with glutamate $(10 \mathrm{~mm}$ L-glutamic acid, $\mathrm{pH} 8.0,-5.0$ to $30 \mathrm{nA}$ ejection current, $10 \mathrm{nA}$ holding current), or serotonin (20 mM serotonin creati- 
nine sulfate, $\mathrm{pH} 4.0,10-80 \mathrm{nA}$ ejection current, -10 nA holding current). CORT was suspended in $1 \mathrm{ml}$ of sesame oil and injected subcutaneously. All drugs were purchased from Sigma (St. Louis, MO).

Placements of recording sites were marked by iontophoretically depositing Pontamine Sky Blue. Animals were perfused with $10 \%$ formalin and post-fixed, and brains were cut on a sliding microtome into $50-\mu \mathrm{m}-$ thick sections. Sections were Nissl-stained and coverslipped, and the location of the dye spot and stimulating electrodes were determined under light microscopic examination.

Immunocytochemistry. Immunocytochemistry was used to examine the distribution of the GR in several of the amygdala nuclei, as well as to examine any changes in receptor density as a function of CORT level. The LA, B, and CE were focused on primarily. The five treatment groups examined, based on manipulation of CORT dose, were the following: intact (no CORT alterations); ADX; ADX plus $1.0 \mathrm{mg} / \mathrm{kg}$ CORT replacement; ADX plus $5 \mathrm{mg}$ of CORT; and ADX plus $10 \mathrm{mg}$ of CORT.

The primary antibody used to examine the distribution of the GR was a polyclonal (rabbit) anti-human glucocorticoid receptor antibody (GR$57,1 \mu \mathrm{g} / \mathrm{ml}$; Affinity Bioreagents, Golden, CO) that interacts with the activated form of the GR.

Thiry-five rats were used for immunocytochemical examination of GR receptor distribution across the five treatment groups. The number of brains within each groups were broken down as follows: intact, 4; ADX, 4; ADX plus $1.0 \mathrm{mg} / \mathrm{kg}$ CORT replacement, 6; ADX plus $5 \mathrm{mg}$ of CORT, 10; and ADX plus $10 \mathrm{mg}$ of CORT, 11. The ADX group was killed $4-5 \mathrm{~d}$ after surgery. The animals in the ADX plus CORT conditions were killed after completion of electrophysiological experimentation, usually $2-4 \mathrm{hr}$ after CORT injection.

At the time of killing, rats were deeply anesthetized with $0.5 \mathrm{mg} / \mathrm{kg}$ pentobarbital and perfused transcardially with $200 \mathrm{ml}$ of heparinized cold $0.9 \%$ saline, followed by $4 \%$ paraformaldehyde in $0.1 \mathrm{M}$ phosphate buffer. Brains were post-fixed for $24 \mathrm{hr}$ in the same fixative and then sectioned on a vibratome $(50 \mu \mathrm{m})$ into a PBS bath. After rinsing in PBS, sections were transferred to cell wells containing $1 \%$ bovine serum albumin, $\mathrm{pH} 7.2$, for $30 \mathrm{~min}$. The tissue sections were then incubated in primary antibody overnight, rinsed, and placed in the corresponding secondary antibody for 2-4 hr (biotinylated anti-rabbit IgG, Vectastain; Vector Laboratories, Burlingame, CA). Visualization of the immunoreaction used avidin-biotin incubation combined with a diaminobenzamine (DAB) reaction, as in $\mathrm{Li}$ et al., 1996. After immunostaining, sections were mounted on 5\% gelatin-subbed slides and viewed under a light microscope. Controls for each antibody used mismatched secondary antibodies to ensure specificity of the primary label (data not shown).

The effects of CORT treatment on the density of GR-immunoreactive (GR-ir) neurons in the dorsal LA were quantified as per Ahima and Harlen (1991). Briefly, neurons with distinct immunoreactivity in the dorsal LA were counted blindly in a $100 \times 100 \mu \mathrm{m}$ grid at a magnification of $40 \times$ using the Neurolucida Stereo Investigator cell-counting software program (Micro BrightField, Inc., Colchester, VT). Total labeled cell counts were taken and further grouped into nuclear versus cytoplasmic staining. Nuclear immunoreactivity was determined visually as dense, small, and round compartmentalized staining, and cytoplasmic immunoreactivity as more diffuse, granular, and asymmetric. Three brains were used in each CORT condition, and three randomly selected sections were chosen from each brain corresponding to Paxinos and Watson (1986), their Figures 27-30. The mean and SE per control or CORT treatment group was determined from pooled counts, and data was analyzed using a one-way ANOVA and Neuman-Keuls post hoc analysis.

\section{RESULTS}

\section{Electrophysiology}

Neurons in the LA were either silent or had low-firing rates $(<5$ $\mathrm{Hz}$ ), as is typical for this region (Clugnet et al., 1990; Bordi and LeDoux, 1992). Stimulation of MGm/PIN and TE3 resulted in biphasic action potentials, with relatively fixed latencies (Clugnet et al., 1990; Bordi and LeDoux, 1992; Bordi et al., 1993; Li et al., 1996). MGm/PIN stimulation resulted in a single spike at a latency of 4-20 msec, whereas TE3 stimulation evoked a spike at 8-25 msec after stimulus onset. The known monosynaptic inputs to LA from the MGm and TE3 regions are glutamatergic and are presynaptic to NMDA and AMPA receptors, although the MGm pathway recruits a larger NMDA component (Li et al., 1996; Farb and LeDoux, 1997; M. W. Weisskopf and J. E. LeDoux, personal communication). Once LA neurons were identified via synaptic stimulation, iontophoretic application of glutamate was used to evoke action potentials.

Of the 117 neurons studied, 76 were activated by MGm stimulation, 86 by TE3 stimulation, and 64 by local application of glutamate. Many neurons could be activated from more than one source of stimulation. The neurons studied were dispersed across the five treatment groups: intact $(n=24)$; $\mathrm{ADX}(n=32)$; ADX plus $1 \mathrm{mg} / \mathrm{kg}$ CORT $(n=17)$; ADX plus $5 \mathrm{mg}$ of CORT $(n=$ $25)$; and ADX plus $10 \mathrm{mg}$ of CORT $(n=19)$. Neurons in the ADX group were recorded from before the CORT injections, allowing for before and after CORT effects to be observed in the same animal. In six cases, the same neuron was held and recorded from both before and $1 \mathrm{hr}$ after the CORT injection, and in four of those cases, the effects of 5-HT on glutamatergic activity was measured.

In all conditions, the effects of iontophoretically applied 5-HT were tested on neurons activated either synaptically and/or via glutamate application. Perievent time histograms (PETH) were constructed by accumulating the number of LA spikes elicited by a single pulse stimulus to the MGm or TE3 regions for 3 min $(0.3$ $\mathrm{Hz}$ ) or by accumulating total number of spikes evoked during glutamate application. After accumulating spikes during this control period, 5-HT was concurrently applied during these conditions, and the total number of spikes was again collected and compared with the control period. If there was a substantial change in evoked activity as a result of 5-HT, a 3-10 min recovery period was allowed, after which spikes were again counted. Representative individual PETH for the intact groups are shown in Figure 2, demonstrating the inhibitory effects of 5-HT on synaptically and glutamate-evoked LA neurons.

The effects of 5-HT application on evoked LA activity depended on the presence of the adrenal glands and varied as a function of CORT replacement in ADX animals. In intact animals, 5-HT was generally inhibitory. In the ADX group, 5-HT no longer had an inhibitory effect. This effect was also absent in the ADX plus $1 \mathrm{mg} / \mathrm{kg}$ CORT group. In the higher CORT replacement groups (5 and $10 \mathrm{mg}$ ), 5-HT again inhibited LA responses. There were a few cases in which 5-HT had an excitatory effect, primarily in the ADX plus $1 \mathrm{mg}$ of CORT group, perhaps reflecting a type I mineralocorticoid receptor (MR)-mediated effect. Representative individual histograms for the intact, ADX, low-CORT (ADX plus $1 \mathrm{mg}$ of CORT), and high-CORT (ADX plus $10 \mathrm{mg}$ of CORT) groups are shown in Figure 3. Statistical analysis of firing-rate changes as a function of 5-HT application revealed several significant effects across CORT replacement doses within each stimulation paradigm (Fig. 4.). Data were normalized by subtracting the number of spikes evoked during 5-HT application from the preceding control period. In the glutamate group, a one-way ANOVA revealed a significant effect of CORT dose on number of spikes evoked during 5-HT application versus the preceding control period $(F=5.14$; $p<0.01)$. Newman-Keuls post hoc analysis demonstrated the intact group differed significantly from the ADX $(p<0.05)$ and ADX plus $1 \mathrm{mg}$ of CORT $(p<0.05)$ groups but was no different from the ADX plus 5 and $10 \mathrm{mg}$ of CORT groups during 5-HT application.

Analysis of MGm-evoked activity also revealed significant difference between group dose effects $(F=4.07 ; p<0.01)$. Post hoc analysis demonstrated that the intact group was significantly different from the ADX group $(p<0.05)$ and was nearly signif- 
A. Iontophoresis of Glutamate and 5-HT

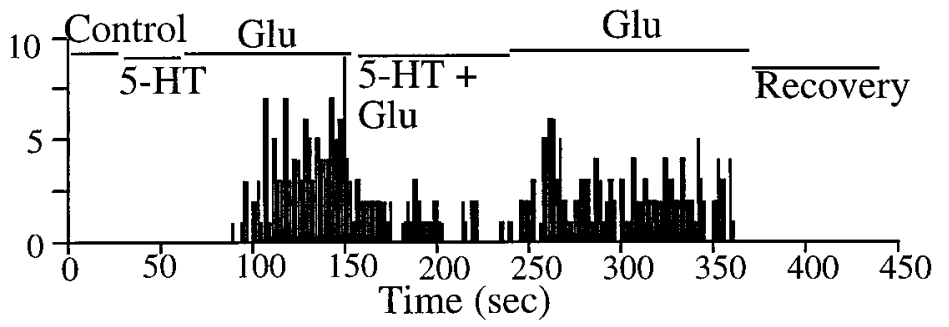

B.

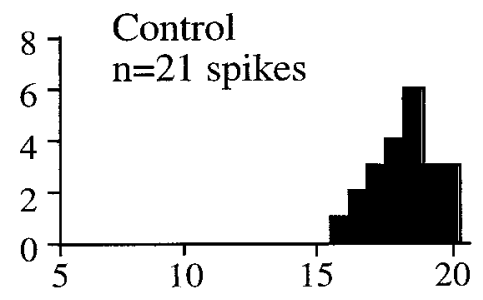

C.

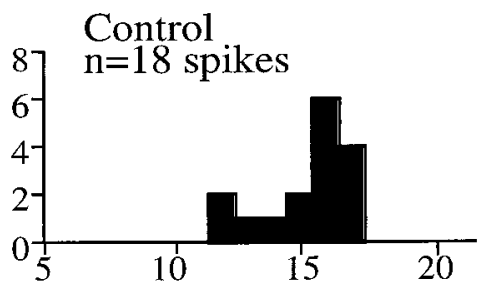

MGm Stimulation

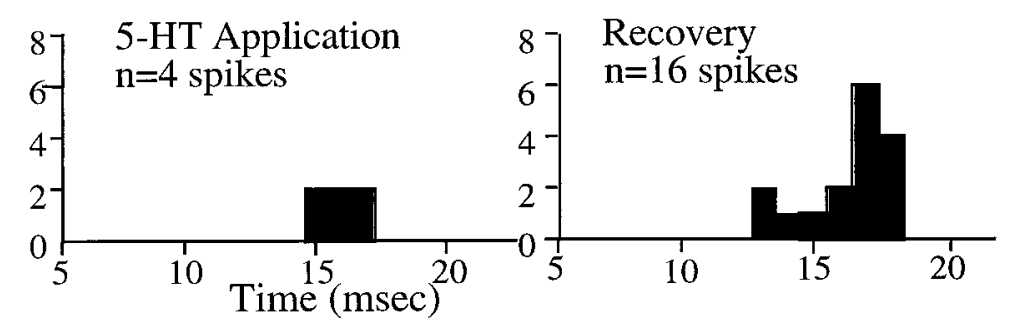

TE3 Stimulation

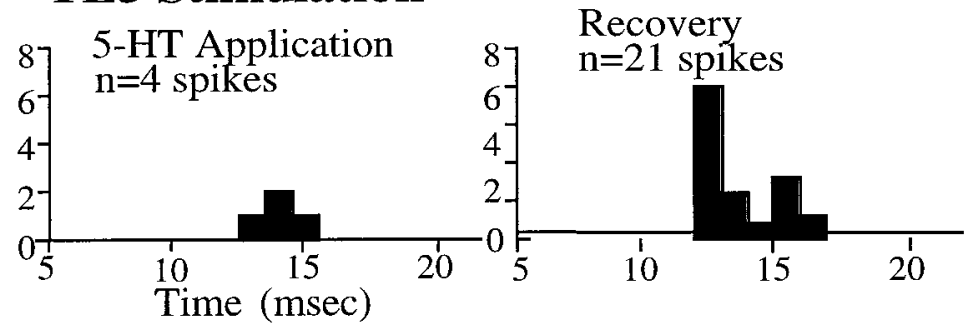

Figure 2. Representative histograms demonstrating the effects of 5-HT on synaptically and glutamate-evoked activity on LA neurons in the intact animal. A, Local iontophoretic application of glutamate evokes action potentials in a normally quiescent neuron, and concurrent application of 5-HT inhibits this glutamate-evoked activity. $B$, Stimulation of the MGm/PIN evokes action potentials in LA neurons. However, during local application of 5-HT, synaptically evoked activity is inhibited. $C$, Stimulation of TE3 evokes action potentials in LA neurons, and these are inhibited by local application of 5-HT.

icantly different from the ADX plus $1 \mathrm{mg} / \mathrm{kg}$ CORT group $(p=$ $0.07)$. The intact group was not different from the high-CORT replacement groups.

For the TE3-evoked spikes between all dose groups, similar patterns were observed. However, statistical significance was not achieved because of the high variance in the ADX plus $10 \mathrm{mg}$ of CORT group. If this group is removed, a statistical difference is then seen among the remaining groups $(F=3.14 ; p<0.05)$. Post $h o c$ analysis demonstrated that the intact group differs from the ADX group $(p<0.05)$ and is no different from the $5 \mathrm{mg}$ of CORT replacement dose group.

A summary of mean firing rates across all conditions is shown in Table 1. In all ADX conditions, baseline evoked activity was not significantly affected by the loss of endogenous CORT, with the exception of the ADX glutamate baseline, which may be a reflection of the high variance seen with this data. Consistent glutamate current levels and stimulation parameters were used throughout all manipulations.

\section{Immunocytochemistry}

Immunocytochemistry using polyclonal antibodies against the GR were done in five groups: intact, ADX, and ADX with replacement CORT (1 $\mathrm{mg} / \mathrm{kg}, 5 \mathrm{mg}$, and $10 \mathrm{mg})$. Staining was examined at the light microscopic level to determine the intracellular receptor distribution and its translocation between cyto- plasm and nucleus as a function of CORT level. In particular, examination of the intact rat shows concentrated GR staining levels in the CE, with moderate levels in the B and LA, which is consistent with previous studies (Ahima and Harlen, 1991; Honkamiemi and Pelto-Huikko, 1992). However, an examination of activated GR distribution in the different nuclei of the amygdala and of the sensitivity of various replacement doses of CORT on GR reinstatement across the different amygdala nuclei has not been previously examined.

There was a significant main effect of CORT dose on the number of GR-ir cells in all regions examined (total cells counted, $F_{(4)}=14.59 ; p<0.001$; cytoplasmic, $F_{(4)}=10.12 ; p<0.001$; and nuclear, $\left.F_{(4)}=10.98 ; p<0.001\right)$. The micrographs displayed in Figure 5 illustrate the effect of CORT manipulation on LA neurons, demonstrating the absence of activated type II receptors in the ADX and low-CORT groups and the dense nuclear staining present in the high-CORT groups. Figure 6 shows the quantitative effects of CORT treatment on the total, cytoplasmic, and nuclear counts of GR-57-immunoreactive neurons, indicating the number of neurons in each condition with activated type II receptors. In all regions, ADX significantly reduced the density of GR-ir neurons to essentially undetectable levels. Examining the conditions with CORT present (intact, low, and high CORT), the number of neurons labeled did not change as a function of CORT 
A Glutamate-Evoked Spikes
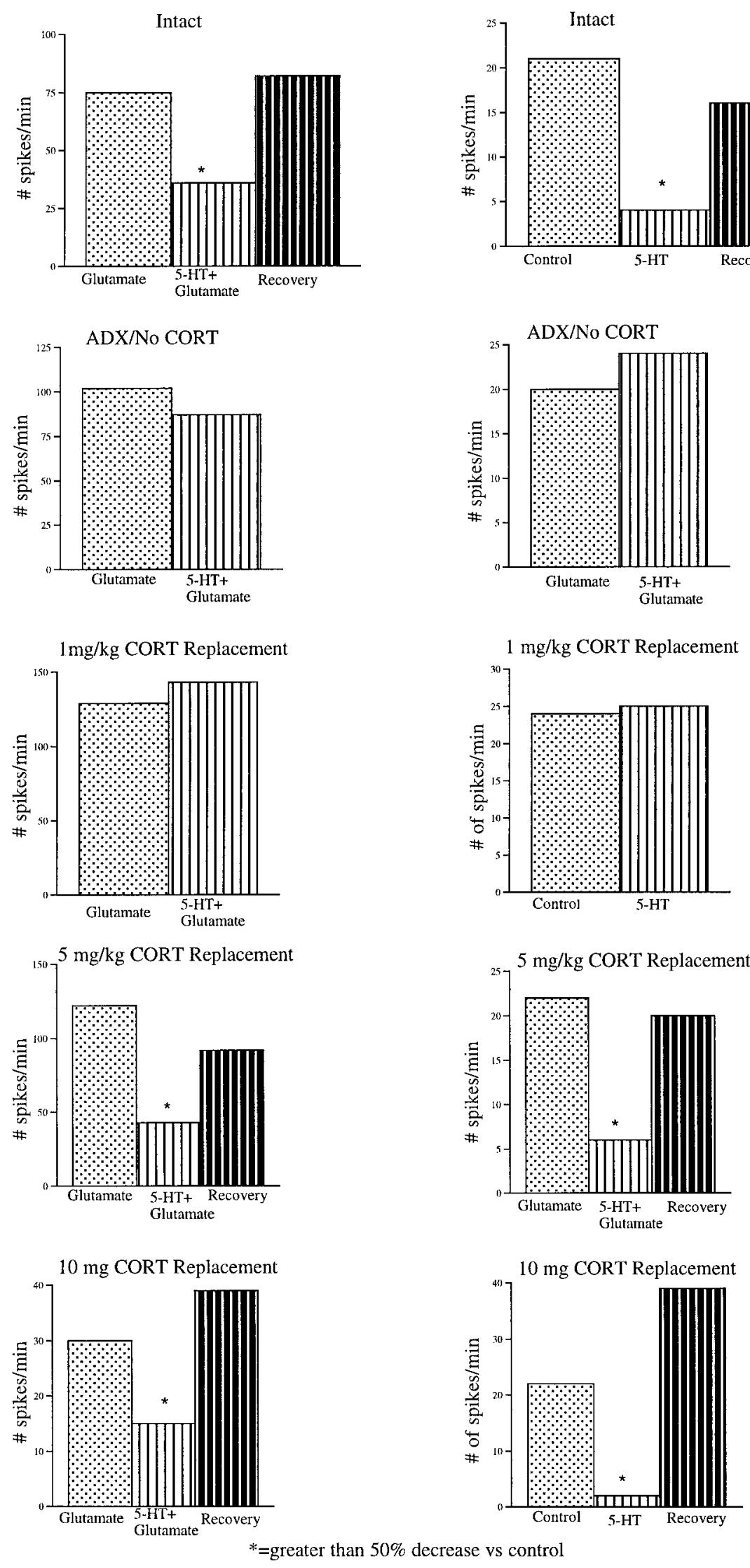

B. MGm-Evoked Spikes
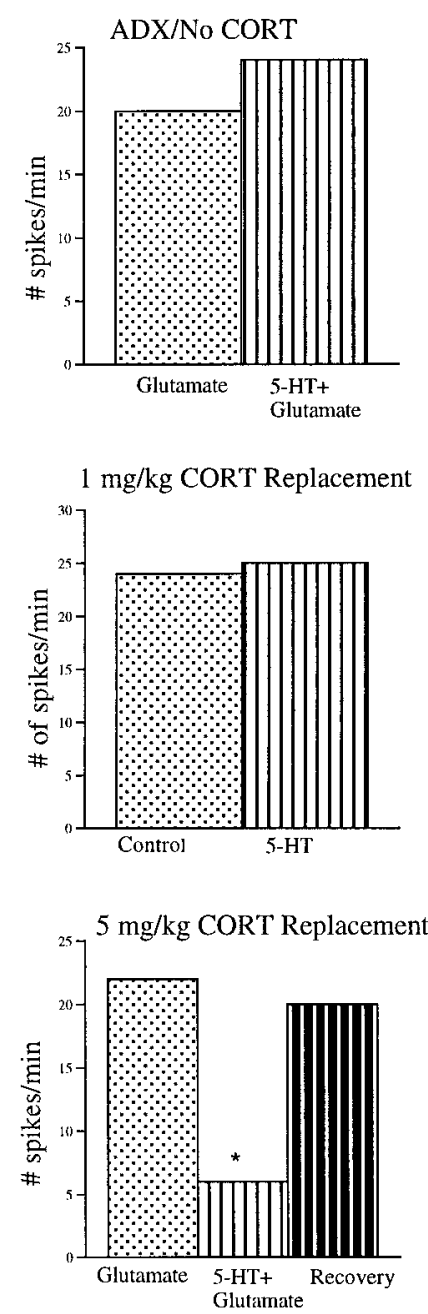

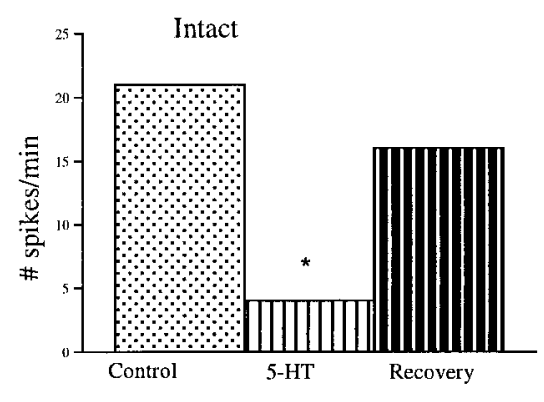

Figure 3. Representative individual histograms showing the effects of local 5-HT application on neurons stimulated synaptically (via pulses to the MGm; TE3 data not shown) or by iontophoretically applied glutamate, as a function of CORT treatment. Recovery groups shown only when there was more than a 50\% decrease in firing rate with serotonin application. $A$, In this intact animal, glutamate-activated neurons were inhibited by 5-HT $>50 \%$ compared with the preceding control period. However, in the ADX animal with $1 \mathrm{mg} / \mathrm{kg}$ replacement, locally applied 5-HT did not inhibit glutamate-evoked spikes. In the ADX animals with 5 or $10 \mathrm{mg}$ of CORT replacement, evoked spikes were inhibited by 5 -HT application. $B$, In this intact animal, 5-HT application inhibited MGm-evoked action potentials by $>50 \%$. In this ADX animal, synaptically evoked spikes via MGm stimulation were not inhibited by local 5-HT application with $1 \mathrm{mg} / \mathrm{kg}$ CORT replacement. However, with higher-CORT replacement $(5$ or $10 \mathrm{mg}$ ), the inhibitory effects of 5 -HT were reinstated. 
A. Glutamate

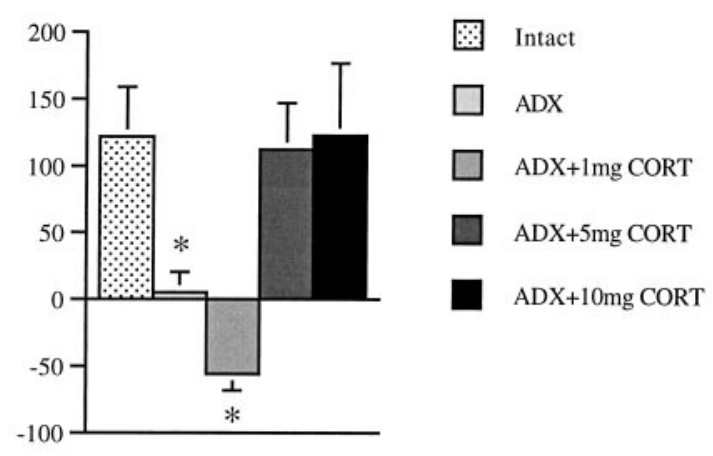

B.

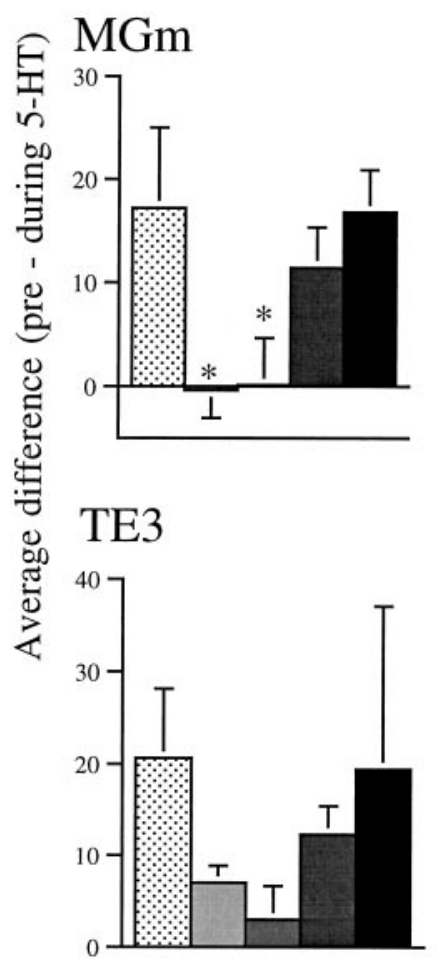

Figure 4. Bar graphs demonstrating the effects of 5-HT on evoked spikes by subtracting the number of spikes evoked during 5-HT application from the preceding control period. $A$, A significant effect of dose is seen in the number of spikes evoked by glutamate during 5-HT application. In the intact, ADX plus $5 \mathrm{mg}$ of CORT, and ADX plus $10 \mathrm{mg}$ of CORT groups, there is a large decrease in the number of spikes evoked during 5-HT application. However, in the ADX group, very little difference is seen between the control and 5-HT application period, and in the ADX plus 1 $\mathrm{mg}$ of CORT group, there is a trend toward an increase in the level of activity. $B$, In the MGm-stimulated neurons, a significant effect of dose is also seen in the number of spikes evoked during 5-HT application. In the intact, ADX plus $5 \mathrm{mg}$ of CORT, and ADX plus $10 \mathrm{mg}$ of CORT groups, a large decrease in the number of spikes evoked during 5-HT application is seen. However, in the ADX and ADX plus $1 \mathrm{mg}$ of CORT groups, very little difference is seen between the control and 5-HT application period. $C$, Of the neurons activated by TE3 stimulation, there was not a significant effect of dose. However, this is because of the large degree of variance in the $10 \mathrm{mg}$ of CORT group. The overall pattern of responses is similar to the glutamate and TE3 groups, with only the intact, ADX plus $5 \mathrm{mg}$ of CORT, and ADX plus $10 \mathrm{mg}$ of CORT groups showing a decrease in the number of spikes evoked during 5-HT application. * $p<0.05$

dose, with only the ADX group exhibiting a significant decrease (Fig. 6A). However, significant dose effects are seen with the examination of cytoplasmic versus nuclear staining. Counting neurons with only cytoplasmic staining (Fig. 6B), the intact and
low-CORT groups do not differ from each other, yet the highCORT groups are significantly different from intact $(p<0.05)$, the $5 \mathrm{mg}$ group is significantly different from the $1 \mathrm{mg} / \mathrm{kg}$ group $(p<0.05)$, and the $10 \mathrm{mg}$ group approaches significance $(p=$ 0.06). This trend reverses when nuclear staining is counted (Fig. $6 C)$. Thus, both high-CORT groups are now significantly higher than the intact and low-CORT groups $(p<0.05)$.

\section{DISCUSSION}

The main focus of this study was to examine the interaction of the adrenal steroid CORT with 5-HT in influencing excitatory activity in the amygdala, proposing that auditory sensory inputs are modulated by 5-HT receptors and peripheral stress hormones. Our findings demonstrated that 5-HT was consistently inhibitory in intact animals but had no effect after removal of endogenous CORT via ADX. ADX also eliminated nuclear staining of CORT receptors in the LA. Replacement of high doses of CORT reinstated the inhibition and also led to the return of dense nuclear staining.

\section{5-HT inhibits afferent excitation in the LA}

Our initial finding was that 5-HT inhibits glutamate-evoked activity in the LA. Anatomical studies have shown that the amygdala receives a dense serotonergic projection from the dorsal raphe nucleus, and activation of the dorsal raphe increases 5-HT levels in the amygdala (Chaoloff, 1993; Kawahara et al., 1993). Specific 5-HT receptor subtypes are also distributed in the amygdala. The $5-\mathrm{HT}_{1 \mathrm{~A}}$ receptor is found predominantly in the $\mathrm{CE}$, whereas the $5-\mathrm{HT}_{2}$ and $5-\mathrm{HT}_{3}$ receptors are found in the $\mathrm{B}$ and LA (Pazos and Palacios, 1985; Radja et al., 1991, Morales and Bloom, 1997). A possible mode of action for this 5-HT inhibition could take several forms. One mechanism is direct inhibition via activation of inhibitory $5-\mathrm{HT}_{2}$ receptors located on neurons recorded from, although it is not clear on what cell types or where on the neurons these receptors would be. Another possibility is indirect inhibition via activation of GABAergic interneurons. It is known that the $5-\mathrm{HT}_{3}$ receptor is found on these interneurons (Morales and Bloom, 1997) and is a fast excitatory receptor in the amygdala (Sugita et al., 1992). In support of this model, preliminary data from this lab has shown that iontophoretic administration of $\mathrm{GABA}_{\mathrm{A}}$ and $\mathrm{GABA}_{\mathrm{B}}$ antagonists blocks the inhibitory effects of 5-HT on glutamate-activated LA neurons (Stutzmann and LeDoux, 1998)

\section{CORT is necessary for 5-HT inhibition}

If endogenous CORT is removed, 5-HT no longer has an inhibitory effect on glutamatergic activity, suggesting that this hormone plays a key role in maintaining serotonergic-mediated modulation. With acute high levels of replacement CORT, the actions of 5-HT are fully reinstated to control levels. Low doses of replacement CORT were not effective. Although ADX removes other hormones in addition to CORT, the replacement of CORT fully restores the effects of 5-HT, strongly supporting the role of this particular adrenal hormone in modulating serotonergic activity in the LA.

We found no clear effect of ADX or acute CORT replacement on glutamatergic transmission at the single unit extracellular recording level. In the ADX group, iontophoretic glutamateinduced firing rates were lower than the other treatment groups. However, it is unclear whether this is a CORT-mediated effect. Importantly, synaptically induced firing rates in the ADX group did not differ from the remaining treatment groups, suggesting 


\begin{tabular}{|c|c|c|c|c|c|}
\hline & Intact & ADX & ADX plus $1 \mathrm{mg}$ of CORT & ADX plus $5 \mathrm{mg}$ of CORT & ADX plus $10 \mathrm{mg}$ of CORT \\
\hline \multicolumn{6}{|c|}{ Glutamate-evoked spikes } \\
\hline Pre & $203.5(37.4)$ & $73.3(12.4)$ & $176.7(39.9)$ & $182.0(43.8)$ & $192.4(57.0)$ \\
\hline During & $81.6(23.4)$ & $68.2(18.1)$ & $232.6(44.2)$ & $69.6(15.2)$ & $69.4(24.2)$ \\
\hline \multicolumn{6}{|c|}{ MGm-evoked spikes } \\
\hline Pre & $47.4(5.8)$ & $51.3(4.0)$ & $55.5(6.1)$ & $44.1(5.4)$ & $43.1(5.9)$ \\
\hline During & $30.2(4.9)$ & $51.7(3.9)$ & $55.5(4.3)$ & $32.6(6.9)$ & $26.3(5.6)$ \\
\hline \multicolumn{6}{|c|}{ TE3-evoked spikes } \\
\hline Pre & $49.2(4.5)$ & $51.4(3.6)$ & $44.0(6.1)$ & $37.9(3.4)$ & $44.4(4.8)$ \\
\hline During & $28.6(4.6)$ & $44.4(3.4)$ & $41.0(4.1)$ & $25.7(4.6)$ & $29.9(6.3)$ \\
\hline
\end{tabular}

that glutamatergic transmission from auditory afferents is not primarily affected at this level of observation. Regardless, 5-HT was primarily effective in inhibiting glutamate activity in the intact and high-CORT groups and had little effect in the ADX groups.

The immunocytochemistry conducted in this study supports the involvement of the CORT type II receptor in the observed physiology. The changes in the anatomical localization of activated type II receptors varied as a function of CORT dose. Under normal and stress levels of circulating CORT, 5-HT serves to inhibit excitatory auditory input to the LA, and this corresponds to dense nuclear GR immunolabeling in this region. With no or low levels of CORT, 5-HT no longer modulates this glutamatergic activity, and this occurs in conjunction with low or no GR labeling. Yet, regardless of intracellular localization, the number of GR-ir neurons remains fairly constant across CORT levels, which may suggest that the number of GR does not vary significantly but will change intracellular location as a function of CORT levels.

This conclusion is consistent with previous studies, suggesting that GR receptors, which are normally bound to the nuclear membrane, will cross into the cytoplasm after removal of endogenous CORT and move back to the nucleus with replacement injections of CORT (Ahima and Harlan, 1991, 1992). Although the level of immunoreactive staining does not necessarily reflect the endogenous concentration of GR, it is indicative of its relative amount among CORT doses and intracellular compartmentalization. An interesting phenomenon is that the high-CORT groups demonstrate predominantly higher levels of nuclear staining than the intact and low-CORT groups, yet the observed physiology of the intact and high-CORT groups are most similar. This may reflect differences in the length of exposure to CORT. The administration of a single large dose of CORT in the ADX animal will likely have time to induce transcription of some proteins involved in the observed physiological effects recorded a few hours later. However, this is not necessarily the quantitative equivalent of the mechanisms long in place of an intact animal that has relatively constant levels of CORT present over time (B. McEwen, personal communication).

The larger body of adrenal steroid research conducted in the hippocampus (Mitchell et al., 1992; Joels, 1997; but see Roozendaal et al., 1992; Roozendaal and McGaugh, 1997) may provide some key insights into the amygdala mechanisms observed in this study. An interesting dynamic exists in the CA1 region of the hippocampus in which CORT influences $5-\mathrm{HT}_{1 \mathrm{~A}}$ receptor-mediated synaptic input. Without corticosteroid manipulation, local application of 5-HT induces a membrane hyperpo- larization. However, with type I receptor occupation, the amplitude of the 5-HT-induced hyperpolarization is reduced, and with type II receptor occupation (during elevated CORT levels), the 5-HT responses were enhanced. These CORT-5-HT mediated effects are thought to occur at the genomic level (Karst and Joels, 1991; Joels and de Kloet, 1992).

These findings in the hippocampus are consistent with our results in the amygdala, although different serotonin receptor subtypes may be involved. It is possible that CORT maintains the activity of the $5-\mathrm{HT}_{3}$ receptor on inhibitory interneurons. With little or no CORT present, the $5-\mathrm{HT}_{3}$ receptors are insufficient to activate local GABAergic modulation of glutamate activity. However, with basal or stress levels of CORT, glutamatergic sensory input is more effectively filtered to permit relevant stimuli to be processed by the amygdala. A next step in the pursuit of this hypothesis is to measure $5-\mathrm{HT}_{3}$ receptor expression, showing colocalization with type II (GR) and/or type I (MR) in GABA interneurons and determining the role of adrenal steroid replacement on $5-\mathrm{HT}_{3}$ receptor expression. There is a precedent for such a study: the $5 \mathrm{HT}_{1 \mathrm{~A}}$ receptor is biphasically modulated by type I and type II receptors as determined by mRNA, receptor binding, and electrophysiological studies (for review, see Joels, 1997). The mechanisms involved in both the hippocampal and amygdala 5-HT-CORT interactions may not be entirely dissimilar. In both cases, type II receptor occupation facilitates the intrinsic modulatory patterns of each receptor subtype. The hyperpolarizing effects of $5 \mathrm{HT}_{1 \mathrm{~A}}$ receptor are enhanced with type II receptor occupation, whereas enhancement of the excitatory $5-\mathrm{HT}_{3}$ receptor can be inferred via facilitation of GABAergic inhibition.

\section{Functional implications}

The inhibition of afferent excitation of 5-HT in the LA is likely to play an important role in information processing by the amygdala. In the intact animal, mechanisms or stimuli that enhance 5-HT release in the LA (such as stress-induced central CORT release) can serve to selectively modulate incoming stimuli before it is fully processed by the amygdala and affect downstream responses initiated by the CE.

For example, glutamatergic transmission plays a crucial role in amygdala processing and plasticity (Li et al., 1996; Maren and Fanselow, 1996; Rogan and LeDoux, 1996), and its modulation can influence amygdala-dependent functions, such as fear conditioning. Unlike the hippocampus and paraventricular nucleus of the hypothalamus, which downregulate stress mechanisms, the amygdala appears to have a facilitatory role on the stress response (Honkamiemi and Pelto-Huikko, 1992; Fuchs and Flugge, 1995; Pich et al., 1995; Watts and Sanchez-Watts, 1995). Chronic CORT 

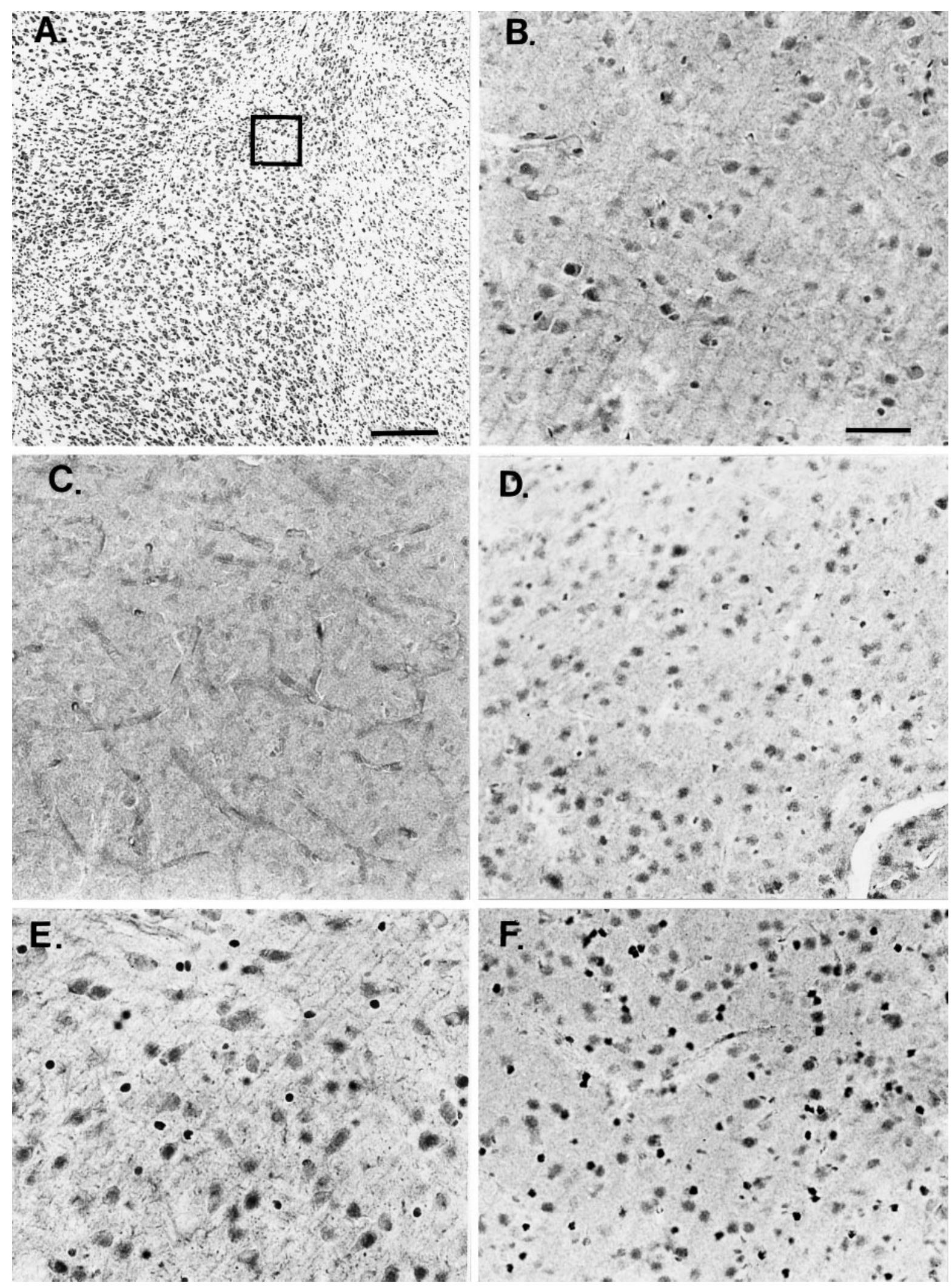

Figure 5. A, Nissl-stained section of the LA and surrounding regions (low power, $5 \times$ objective). Area of detail shown in the immunolabeled sections is outlined. Scale bar, $200 \mu \mathrm{m}$. B, Photomicrographs of GR immunolabeling in the lateral amygdala (high power, $20 \times$ objective). Scale bar, $50 \mu \mathrm{m}$. In the intact animal, GR distribution is found throughout the LA and is concentrated in the cell nuclei in its activated form (as labeled with the GR-57 antibody). There is a change in distribution of the type II GR in several of the amygdala nuclei as a function of CORT dose. $C$, In the ADX brain with no endogenous CORT, nuclear labeling of the GR with the GR-57 antibody essentially disappears. $D$, ADX with 1 mg of CORT replacement shows a GR distribution pattern with more sparse nuclear staining in the lateral amygdala. E, ADX with 5 mg of CORT results in a strong reinstatement of nuclear GR labeling. $F$, Similar to the $5 \mathrm{mg}$ group, $10 \mathrm{mg}$ of CORT replacement results in dense nuclear GR staining in the LA. * $p<0.05$. 

A. Total Number of GR labeled cells
B. Cytoplasmic GR labeling
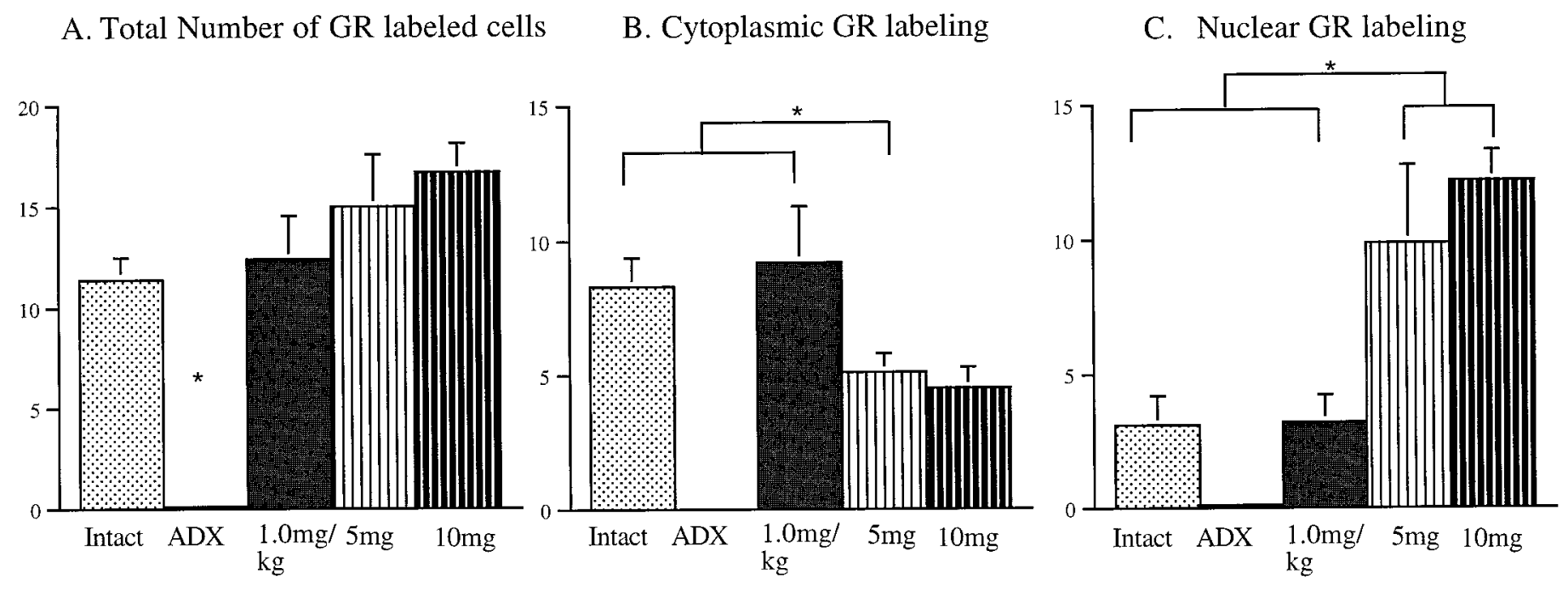

*=significantly different, $\mathrm{p}<0.05$

Figure 6. Bar graphs showing the density of GR-ir cells in the dorsal LA across varying levels of CORT manipulation. Number of labeled cells, exclusively cytoplasmic, and exclusively nuclear staining patterns were distinguished. In all regions examined in all CORT treatment groups, the ADX group demonstrated essentially no detectable GR-ir levels. $A$, A count of the number of GR-labeled cells demonstrated a significant difference in the ADX condition, with no differences among the remaining conditions. $B$, Counting cells with only cytoplasmic staining, the intact and low-CORT conditions contain the same number of cells, and these groups are significantly higher than the $5 \mathrm{mg}$ of CORT group and approaching significance in the $10 \mathrm{mg}$ of CORT group. $C$, Counting cells with only nuclear staining, the high-CORT groups are now significantly higher than the intact and low-CORT group.

treatment potentiates amygdala-dependent fear-conditioning responses (Corodimas et al., 1994; C. Conrad, personal communication) but decreases performance on hippocampal-dependent spatial tasks (Shors and Dryver, 1992; Conrad et al., 1996) and impairing neuronal plasticity in the hippocampus (Shors et al., 1990; Pavlides et al., 1995).

In summary, we propose that excitatory auditory sensory signals are modulated by serotonergic receptors and peripheral stress hormones in the LA. These substances, in other words, change the sensitivity of amygdala neurons to the stimuli that are activating them. Clarification of the influence of serotonin over sensory processing by the amygdala would be an important step in understanding how stimuli are processed by the amygdala and how autonomic, endocrine, and behavioral responses are regulated by this system. This complex interaction between glutamatergic sensory input, serotonergic modulation, and a CORTmediated gain control can serve as the basis of an adaptive behavioral state in which during periods of stress or fear, incoming sensory signals can be adjusted to maximize awareness or perception of important signals in the environment.

\section{REFERENCES}

Ahima R, Harlan R (1991) Differential corticosteroid regulation of type II glucocorticoid receptor-like immunoreactivity in the rat central nervous system: topography and implications. Endocrinology 129:226-236.

Ahima R, Harlan R (1992) Charting of Type II glucocorticoid receptorlike immunoreactivity in the rat central nervous system. Neuroscience 39:579-604.

Axelrod J, Reisine T (1984) Stress hormones: their interaction and regulation. Science 224:452-459.

Boadle-Biber M, Singh V, Corley K, Phan T, Dilts R (1993) Evidence that corticotropin-releasing factor within the extended amygdala mediates the activation of trytophan hydroxylase produced by sound stress in the rat. Brain Res 628:105-114.

Bordi F, LeDoux J (1992) Sensory tuning beyond the sensory system: an initial analysis of auditory properties of neurons in the lateral amygda- loid nucleus and overlying areas of the striatum. J Neurosci 12:24932503

Bordi F, Clugnet M, Pavlides C, LeDoux J (1993) Single unit activity in the lateral nucleus of the amygdala and overlying areas of the striatum in freely-behaving rats: rates, discharge patterns, and responses to acoustic stimuli. Behav Neurosci 107:757-769.

Chaoloff F (1993) Physiopharmacological interactions between stress hormones and central serotonergic system. Brain Res Rev 18:1-31.

Clugnet M, LeDoux J, Morrison S (1990) Unit responses evoked in the amygdala and striatum by electrical stimulation of the medial geniculate body. J Neurosci 10:1055-1061.

Conrad C, Galea L, Kuroda Y, McEwen B (1996) Chronic stress impairs rat spatial memory on the $\mathrm{Y}$ maze, and this effect is blocked by tianeptine pretreatment. Behav Neurosci 110:1321-1334

Corodimas K, LeDoux J, Gold P, Schulkin J (1994) Corticosterone potentiation of learned fear. Ann NY Acad Sci 746:392-393.

Curzon G (1988) Serotonergic mechanisms of depression. Clin Neuropharmacol 2:S11-S20.

Davis M (1992) The role of the amygdala in conditioned fear. In: The amygdala: neurobiological aspects of emotion, memory and mental dysfunction (Aggleton JP, ed). New York: Wiley.

Davis M (1994) The role of the amygdala in emotional learning. Int Rev Neurobiol 36:225-266.

Farb C, LeDoux J (1997) NMDA and AMPA receptors are postsynaptic to auditory thalamic afferents. Synapse 27:106-121.

Farb C, Aoki C, LeDoux J (1995) Differential localization of NMDA and AMPA receptor subunits in the lateral and basal nuclei of the amygdala: a light and electron microscopic study. J Comp Neurol 362:86-108.

Fuchs F, Flugge P (1995) Modulation of binding sites for corticotropinreleasing hormone by chronic psychosocial stress. Psychoneuroendocrinology 20:33-51.

Gray T (1993) Amygdaloid CRF pathways. Role in autonomic, neuroendocrine, and behavioral responses to stress. Ann NY Acad Sci 697:53-60.

Herman J, Patel P, Akil H, Watson S (1989) Localization and regulation of glucocorticoid and mineralcorticoid mRNAs in the hippocampal formation of the rat. Mol Endocrinol 3:1886-1894.

Honkamiemi J, Pelto-Huikko M (1992) Colocalization of peptide and glucocorticoid receptor immunoreactivities in rat central amygdaloid nucleus. Neuroendocrinology 55:451-459. 
Inoue T, Koyama T, Yamashita I (1993) Effect of conditioned fear stress on serotonin metabolism in the rat brain. Pharmacol Biochem Behav 44:371-374.

Joels M (1997) Steroid hormones and excitability in the mammalian brain. Front Neuroendocrinol 18:2-48.

Joels M, de Kloet E (1992) Control of neuronal excitability by corticosteroid hormones. Trends Neurosci 15:25-30.

Kapp B, Whalen P, Supple W, Pascoe J (1992) The role of the amygdala in conditioned fear. In: The amygdala: neurobiological aspects of emotion, memory and mental dysfunction (Aggleton JP, ed). New York: Wiley.

Karst H, Joels M (1991) The induction of corticosteroid actions on membrane properties of hippocampal CA1 neurons requires protein synthesis. Neurosci Lett 11:27-31.

Kawahara H, Yoshida M, Yokoo H, Nishi M, Tanaka M (1993) Psychological stress increases serotonin release in the amygdala and prefrontal cortex assessed by in vivo microdialysis. Neurosci Lett 162:81-84.

Laaris N, Haj-Dahmane S, Hamon M, Lanfumey L (1995) Glucocorticoid receptor-mediated inhibition by corticosterone of $5-\mathrm{HT}_{1 \mathrm{~A}}$ autoreceptor functioning in the rat dorsal raphe nucleus. Neuropharmacology 34:1201-1210.

LeDoux J (1994) The amygdala: contributions to fear and stress. Semin Neurosci 6:231-237.

LeDoux J (1996) The emotional brain: clues from fear conditioning. In: Perception, memory and emotion: frontiers in neuroscience (Ono T, McNaughton BL, Molotchnikoff S, Rolls ET, Nishijo H, eds), pp 513-524. Cambridge, UK: Cambridge UP.

LeDoux J, Cicchetti P, Xagoraris A, Romanski L (1990) The amygdaloid nucleus: sensory interface of the amygdala in fear conditioning. J Neurosci 10:1062-1069.

Li X, Phillips R, LeDoux J (1995) NMDA and non-NMDA receptors contribute to synaptic transmission between the medial geniculate body and the lateral nucleus of the amygdala. Exp Brain Res 105:87-100.

Li X, Stutzmann G, LeDoux J (1996) Convergent but temporally separated inputs to lateral amygdala neurons use different postsynaptic receptors: in vivo intracellular and extracellular recordings in fear conditioning pathways. Learn Mem 3:229-242.

Maren S, Fanselow M (1996) The amygdala and fear conditioning: has the nut been cracked? Neuron 16:237-240.

McEwen B, Sapolsky R (1995) Stress and cognitive functioning. Curr Opin Neurobiol 5:205-216.

McEwen B, Chao H, Rostene W (1986) Adrenal steroid receptors and actions in the nervous system. Physiol Rev 66:1122-1188.

McKittrick C, McEwen B (1996) Regulation of serotonergic function in the CNS by steroid hormones and stress. CNS neurotransmitters and neuromodulators neuroactive steroids, pp 37-76. New York: CRC.

Meltzer H, Lowy M (1987) The serotonin hypothesis of depression. In: Psychopharmacology: the third generation of progress (Meltzer H, ed), pp. 513-526. New York: Raven.

Mendelson S, McEwen B (1992) Autoradiographic analyses of the effects of adrenalectomy and corticosterone on $5-\mathrm{HT}_{1 \mathrm{~B}}$ receptors in the dorsal hippocampus and cortex of the rat. Neuroendocrinology 55:444-450.

Mitchell J, Betito K, Rowe W, Boksa P, Meaney M (1992) Serotonergic regulation of type II corticosteroid receptor binding in hippocampal cell cultures: evidence for the importance of serotonergic-induced changes in cAMP levels. Neuroscience 48:631-639.

Morales M, Bloom F (1997) The 5- $\mathrm{HT}_{3}$ receptor is present in different subpopulations of GABAergic neurons in the rat telencephalon. J Neurosci 17:3157-3167.

Pavlides C, Watanabe Y, Margarinos A, McEwen B (1995) Opposing roles of Type I and Type II adrenal steroid receptors in hippocampal long term potentiation. Neuroscience 68:387-394.

Paxinos G, Watson C (1986) The rat brain in stereotaxic coordinates. Sydney: Academic.

Pazos A, Palacios J (1985) Quantitative autoradiographic mapping of serotonergic receptors in the rat brain. I. Serotonin-1 receptors. Brain Res 346:205-230.

Pich E, Lorang M, Yeganeh M, Rodriguez de Fonseca F, Raber J, Koob GF, Weiss F (1995) Increase of extracellular corticotropin-releasing factor-like immunoreactivity levels in the amygdala of awake rats during restraint stress and ethanol withdrawal as measured by microdialysis. J of Neurosci 15:5430-5447.

Pitkanen A, Savander V, LeDoux J (1997) Organization of intraamygdaloid circuits in the rat: an emerging framework for understanding functions of the amygdala. Trends Neurosci 20:517-523.

Popova N, Lobacheva I (1982) Serotonin in the development of pituitary-adrenocortical response to stress. Brain Res 246:217-233.

Radja F, Laporte A, Daval G, Verge D, Gozlan H, Hamon M (1991) Autoradiography of serotonin receptor subtypes in the central nervous system. Neurochem Int 18:1-15.

Rogan M, LeDoux J (1996) Emotion: system, cells and synaptic plasticity. Cell 85:469-475.

Romanski L, LeDoux J (1993) Information cascade from primary auditory cortex to the amygdala: corticortical and corticoamygdaloid projections of temporal cortex in the rat. Cereb Cortex 3:515-532.

Roozendaal B, McGaugh J (1997) Glucocorticoid receptor agonist and antagonist administration into the basolateral but not central amygdala modulates memory storage. Neurobiol Learn Mem 67:176-179.

Roozendaal B, Koolhaas, J, Bohus B (1992) Central amygdaloid involvement in neuroendocrine correlates of conditioned stress responses. J Neuroendocrinol 4:46-52.

Sapolsky R (1996) Why stress is bad for your brain. Science 273:749-750.

Shors T, Dryver E (1992) Stress impedes exploration and the acquisition of spatial information in the eight arm radial maze. Psychobiology 4:247-253.

Shors T, Foy M, Levine S, Thompson R (1990) Unpredictable and uncontrollable stress impairs neuronal plasticity in the rat hippocampus. Brain Res Bull 24:663-667.

Stutzmann G, LeDoux J (1998) GABAergic antagonists block the inhibitory effects of serotonin in the lateral amygdala: a mechanism for modulation of sensory inputs related to fear. Soc Neurosci Abstr 24:706.

Sugita S, Shen K, North R (1992) 5-Hydroxytryptamine is a fast excitatory transmitter at 5- $\mathrm{HT}_{3}$ receptors in rat amygdala. Neuron 8:199-203.

Watts A, Sanchez-Watts G (1995) Region specific regulation of neuropeptide mRNAs in rat limbic forebrain neurones by aldosterone and corticosterone. J Physiol (Lond) 484:721-736. 